\title{
COVID-19 lockdowns and a response model to health, economic and food anxiety
}

\author{
Ashish Vazirani ${ }^{1}$ (D) $\cdot$ Titas Bhattacharjee ${ }^{1}$ \\ Accepted: 17 November 2020 / Published online: 23 November 2020 \\ (C) Springer Science+Business Media, LLC, part of Springer Nature 2020
}

\begin{abstract}
Pandemics create survival uncertainty through infection possibilities, food scarcity, and unemployment. Being the largest democracy in the world, we have explored the response of Indian citizens on the COVID-19's lockdown and defined an anxiety response model using PLS based Structural Equation Modeling(SEM). For a comprehensive understanding, we have measured the response at two levels of individual and government. Though the types of anxieties are related, we observed that a specific response is linked with a specific type of anxiety and all responses are not anxiety-driven. We have found that the response mechanism of Health and Food anxieties follow very different paths and that the role of information is not significant in all anxieties. Our results will help policymakers in understanding how to respond to a crisis and optimize policy implementation accordingly. It will further help the scholars understand the difference in the anxieties caused by the pandemic and the layers of responses individuals take in such situations.
\end{abstract}

Keywords COVID19 $\cdot$ Anxiety $\cdot$ Decision making $\cdot$ Information $\cdot$ Panic

\section{Introduction}

COVID19 (Corona Virus Disease 2019) is an acute respiratory illness with unknown causes that started in Wuhan, China on 17th Nov 2019 (Davidson, 2020; Paules, Marston, \& Fauci, 2020). COVID19 virus capacity to spread and to cause mortality, forced nations to stop international travel, but within the first four months, infection grew across the globe with epicenters (Infected cases) in Italy $(74,386)$, Iran $(27,017)$, and the USA $(68,489)$. To reduce the spread of infection, the WHO recommended to maintain self-hygiene and physical distance. Such viral infection can be disastrous for a populous country like India, which has a poor public healthcare (150 global rank: World Economic Forum) and where majority of the society is marginalized economically. To control the "people to people" spread, a systemic physical distancing through "lockdowns" became a reasonable temporary solution for the Governments. On 19th Mar 2020, the Prime Minister(PM) of India announced a single day lockdown on 22nd Mar, few officials reported it as a masterstroke to protect Indians, but

Ashish Vazirani

mail.vazirani@gmail.com

1 Indian Institute of Technology Kharagpur, Kharagpur, India many, including PM, suggested the one-day lockdown as just the beginning of a long battle. Post announcement, media houses reported hoarding of food, and individuals were observed following the guidelines of wearing masks and using sanitizer. While researchers were still working out to conclude the effectiveness of an old-time malarial drug Hydroxychloroquine (HCQS) on COVID-19, the drug soon became unavailable in the local market as well as on India's leading online pharma stores like $1 \mathrm{mg}$ and PharmEasy. The effect of lockdown's anxiety was visible, as these actions reflected that individuals were trying to respond to uncertainty. In addition to hoarding food and following guidelines, widespread economic anxiety was observed among individuals, especially in the working class, who were scared to lose their jobs in the coming months.

An individual's capacity to address the uncertainty of survival during a pandemic is limited, and few aspects require government support at a systemic level. Individuals can ensure precautionary measures at their end, but a dedicated mechanism may be expected from the Government in the pandemic. We have explored the possibility of a multi-layer response mechanism of anxiety. For a comprehensive understanding of expectations from the Government, we have categorized it into two levels of Primary and Secondary. A minimum level expectation from a Government is to control the spread of the disease through mass-scale testing and by 
providing medical essentials to needy citizens. However, a pandemic may push individuals to over-react with impractical expectations such as deporting Chinese citizens from India, forcing infected doctors to continue to work, etc. These expectations are not essentials to address COVID19 but an over reactiveness to a situation. Hence, at the primary level, the focus is on controlling the spread of the disease, while secondary level focuses on the impractical and unnecessary support.

Information plays a significant role in decision-making. In situations like pandemics, individuals seek information from the environment to confirm the scale of uncertainty. We have also explored the effect of information consumption on the information publication to measure the possibility of the cyclicality of information flow where social media usage is the locus. An individual consumes and publishes information on social media; the presence of a causal effect of consumption on publication will lead to cyclical information flow. These three aspects of Information consumption, publication, and social media usage are defined as information construct. We have explored the individuals' response mechanism of Health, Food, and Economic anxiety after the lockdown announcement at individual and government level. The results have shown that response to anxiety varies with the type of anxiety, and the information construct plays a significant role in the entire process.

\section{Literature and Hypothesis}

Pandemics bring uncertainty at multiple levels and negatively affect an individual's mental health (Duan \& Zhu, 2020). Especially in countries with a larger population with possibly higher number of infections, the spread of COVID-19 can lead to a mental health crisis (Dong \& Bouey, 2020). To overcome this, individuals respond to anxiety (Shigemura, Ursano, Morganstein, Kurosawa, \& Benedek, 2020), especially by following protocols and hoarding food (Huang \& Zhao, 2020). During a pandemic, the role of unpredictability, uncertainty, the seriousness of the disease, misinformation, and social isolation contribute to stress (Zandifar \& Badrfam, 2020), and an individual's response to such uncertainty is triggered by the initial registration of threat stimulus (Beck \& Clark, 1997). To explore the response mechanism within the probable duration to respond, we have kept the sample collection duration of five days, from the day of the announcement of lockdown to the first day of actual lockdown.

The anxiety is linked with the Fear of Missing Out(FOMO), which in the case of Pandemic, is "Missing out Survival." It can be for health, food, or economic Survival. However, information being the key factor for decision making, its consumption can increase anxiety (Rajkumar, 2020). On the effect of information, Asmundson and Taylor (2020) discussed that inaccurate or exaggerated information from the media could increase anxiety and lead to manifest maladaptive behaviors. Further, social media as an accessible source of information is the reason for the spread of misinformation (Wilson \& Chen, 2020) and creating panic during pandemics (McCauley, Minsky, \& Viswanath, 2013). With a lack of control on social media and the respective spread of misinformation, we expect information consumption through social media to scale-up the response of both food hoarding and precautionary actions. To cover a comprehensive scope of information, we have considered the cyclical flow of information within the information construct with variables of social media usage, information consumption, and publication.

We are considering the Cognitive-Neurobiological Information Processing Model (Hofmann, Ellard, \& Siegle, 2012) as a base to define the pandemic response model(Fig. 1) where the information of lockdown triggered the feeling of FOMO, which further caused anxieties at three categories (Economic, Food and Health), Individuals confirmed the information of the status of the threat from environment, and then responded accordingly. Lastly, they look for emotional regulation through religious guidance and publishing information to inform others about the crisis for social value.

We have explored the anxieties in three categories of Health, Economic, and Food as this is the fundamental need for survival. Further, to assess variables during the COVID-19 pandemic, we referred FOMO scale (Przybylski, Murayama, DeHaan, \& Gladwell, 2013), social media usage scale (Sahin, 2018), religious guidance scale (Joseph \& DiDuca, 2007), and food anxiety (Food Insecurity scale: Zerafati et al., 2007). We also added indicators to ascertain a few other perspectives like information consumption, information publication, health anxiety, health actions, economic anxiety, Expectations from the government system, and Food hoarding actions. Further, we have categorized expectations from government in two segments of primary and secondary as per the expected role in ensuring survival. We have defined health actions as the use of sanitizer and mask for precautionary measures and food actions as hoarding of food and essential to reduce survival uncertainty.

Though we have seen the presence of anxiety, does an individual respond to calm the anxiety? In our first hypothesis, we explore the effect of anxiety on actions and how information consumption influences this relationship.

Research Question: Does anxiety results in action, and what role does information consumption plays in such a relationship?

Hla: Health anxiety effects the usage of sanitizer and wearing mask

H1b: Food anxiety effects hoarding of food and essentials

H1c: Health anxiety effects the consumption of pandemic related information 


\section{Lockdown Speech}

-FOMO

-Initiation of Anxiety

\begin{tabular}{l} 
Perception of threat \\
$\qquad$ Health, Economic and Food Anxiety \\
\hline
\end{tabular}

\begin{tabular}{|l}
\hline Confirm \\
\hline Social Media \\
$\cdot$ Information Consumption
\end{tabular}

Response

- Health Action

- Food Hoarding

-Expectation from Government System

\section{Emotional Regulation}

- Information Publication

- Religious Guidance

Fig. 1 Pandemic Response Model

H1d: Food anxiety effects the consumption of pandemic related information

Hle: Information Consumption effects the usage of sanitizer and wearing Mask

H1f: Information Consumption effects hoarding of food and essentials

Access to resources during COVID-19 being a costly adventure, we have explored the effect of economic anxiety on health and food anxiety and further, the possibility of economic anxiety to effect expectations from the Government.

Research Question: Does the economic anxiety affects the Health and Food anxiety, and further, creates expectations from Government?

H2a: Economic anxiety effects Health anxiety

H2b: Economic anxiety effects Food anxiety

H2c: Economic anxiety effects Primary Expectations from Government

H2d: Economic anxiety effects Secondary Expectations from Government

The role of the Government increases during pandemics as individuals look up to higher authorities with a hope to calm down the pandemic situation, but does all types of anxiety have a similar effect on expectations from Government.

Research Question: Does anxiety effects expectations from Government during pandemic?
H3a: Health anxiety effects secondary expectations from Government.

H3b: Health anxiety effects primary expectations from Government

H3c: Food anxiety effects secondary expectations from Government.

H3d: Food anxiety effects primary from Government.

The feeling of FOMO for survival is expected to initiate anxiety and drive responses, but due to the role of various other variables in decision making, we have explored the overall effect of FOMO on anxieties, actions, Government expectations, and information construct.

Research Question: Does FOMO play any role in the pandemic response?

H4a: The experience of FOMO effect Health anxiety H4b: The experience of FOMO effect Food anxiety

H4c: The experience of FOMO effect Health Action

H4d: The experience of FOMO effect Food Action

H4e: The experience of FOMO effect Secondary Expectations from Government

H4f: The experience of FOMO effect Primary Expectations from Government

H4g: The experience of FOMO effect Information Consumption

H4h: The experience of FOMO effect Information Publication

H4i: The experience of FOMO effect Social Media Usage 
Social media being the primary source of information and misinformation, we have explored the impact of social media usage on the pandemic response, specifically on information consumption and health and food action. We expected a cyclic flow of information in pandemics and looked for the effect of information consumption on information publication and of information publication on Social media usage.

Research Question: What role does Social Media play in the Pandemic Response?

\section{H5a: Social Media usage effects Information Consumption \\ H5b: Social Media effects Health Actions \\ H5c: Social Media effects Food Actions \\ H5d: Information publication effects social media usage \\ H5e: Information consumption effects Information publication}

Beyond the government, it is the supernatural power that individuals may seek to calm down anxiety. Some actions may create ethical ambiguity, especially food hoarding, and individuals may seek religious guidance. We have explored the effect of food hoarding, information consumption, and FOMO on the search for religious guidance.

H6a: Food hoarding effect the search for religious guidance

H6b: Pandemic related information consumption effects the search of religious guidance

H6c: FOMO effect the search for religious guidance

Since Jan 2020, information was spreading that the elderly people are at higher risk of dying with COVID19; hence we have explored the effect of age on health anxiety. Further, social media is a trendy source of information, we have also explored the effect of age on social media usage.

Research Question: Does elder individuals have a higher level of Health anxiety and Social media usage?

H7a: Age effects social media usage

H7b: Age effects health anxiety

Female being considered as the food saviour in Indian society, we have explored the effect of Gender on food anxiety and food action.

Research Question: Does gender have an effect on the experience of food anxiety and food action response?

H8a: Female experience higher food anxiety than male H8b: Female have a higher tendency to hoard food than male

\section{Data and Methodology}

The hypothesized framework was tested by using Partial Least Squares-Structural Equation Modeling (PLS-SEM), which is a second-generation structural equation modeling (Wold, 1982), and new compared to other compatible techniques (Gustafsson \& Johnson, 2004). Structural Equation Modeling tests the relationships between the network of constructs, the PLS-SEM is exploratory in nature, where we identify key drivers for the constructs. This technique is a flexible and useful tool for statistical model building as well as predicting (Ringle, Wende, \& Will, 2005) and can deal with both reflective and formative measures. We have used WARP 7.0 software with the Factor-Based PLS Type CFM2 algorithm for the outer model, Warp3 Basic method for calculating the inner model, and Stable3 method for resampling for establishing the model. These three methods are highlighted as most efficient (Kock, 2020) as the Factor-Based PLS Type CFM2 algorithm employs reliabilities from Dijkstra's consistent PLS technique, which improves computation efficiency as well as help to estimate measurement error and true composite weights (Kock, 2017).

\section{Study Participants}

We have considered India's working-class individuals to ascertain the effect of pandemic on anxiety, and how individual's respond to it. A self-administered computer-based questionnaire using a 7 point Likert scale was shared online with the participants to ascertain the thought process to test the proposed model, which comprises the hypothesis mentioned above. The purpose of the study is informed to the participants and consequently responses are taken voluntarily. Furthermore, the response was not linked to the respondent's

Table 1 Acronym used in the manuscript

\begin{tabular}{ll}
\hline Acronym & Variable \\
\hline FM & FOMO \\
SM & Social Media \\
ICon & Information Consumption \\
IPub & Information Publication \\
HAnx & Health Anxiety \\
FAnx & Food Anxiety \\
EcAnx & Economic Anxiety \\
REL & Religion \\
HAct & Health Action \\
FAct & Food Action \\
PriExpec & Primary Expectation \\
SecExpec & Secondary Expectation \\
Age & Age \\
Gen & Gender \\
\hline
\end{tabular}


Table 2 Participants descriptive data

\begin{tabular}{llllll}
\hline Category & & Tot. & Category & Tot \\
\hline \multirow{2}{*}{ Gender } & Male & 144 & Age & $18-25$ & 144 \\
& Female & 237 & & $26-34$ & 198 \\
& Prefer not to say & 3 & & $35-43$ & 27 \\
Marital Status & Married & 120 & & More than 43 & 15 \\
& Unmarried & 264 & Source of COVID19 & WhatsApp & 30 \\
Highest Education & Below Graduation & 9 & news for the first time & & \\
& Graduate & 96 & & TV News & 216 \\
& Masters & 222 & & Facebook & 84 \\
& PhD & 57 & & Friends & 54 \\
\hline
\end{tabular}

identity, and the suggested ethical practices for online surveys were followed (Barchard \& Williams, 2008). Of the 1255 distributed questionnaires between 21st March 2020 to 25th March 2020, 384 valid surveys returned (31\% response rate). As per the Gamma-exponential (Gurland \& Tripathi, 1971) method, the minimum sample size required for the above framework is 377 , hence the sample size of 384 was considered adequate. The following are the statistical details of samples (Tables 1 and 2).

\section{Measurement Model}

For the measurement model, we assess the convergent validity, which is ascertained by examining the loadings, average variance extracted, and the composite reliability (Gholami, Sulaiman, Ramayah, \& Molla, 2013). Though reflective models require each loading to be higher than 0.5 , no such requirement is with the formative model. A formative model is used where the indicators are expected to measure specific attributes of the latent variable, but the indicators are not expected to be highly correlated with the latent variable itself, as indicators are not expected to be highly correlated with one another. All the reflective models' loadings were above 0.5 , and for formative models, the loadings were significant at $p<.01$, hence acceptable. The reliability measure using Composite Reliability(CR) was above (Table 3) the acceptable value of 0.5 and most of the average variance extracted(AVE), a more conservative estimate of the validity of a measurement model, was above or equal to the threshold of 0.5 (Fornell \& Larcker, 1981), but given higher reliability values, AVE values below 0.5 are acceptable (Lam, 2012).

Further, we have checked the discriminant validity using the HTMT ratio, which also considers the correlation between the constructs. If the value of the HTMT is below the threshold value, then discriminant validity is established. Our results were below the threshold limit of 0.80 (Clark \& Watson, 1995; Kline, 2011); hence discriminant validity is established. Though HTMT is a liberal test, it may be adopted when it is challenging to establish empirical differences between distinct constructs (Henseler, Ringle, \& Sarstedt, 2015).

\section{Structural Model}

To assess the structural model, Hair Jr, Sarstedt, Hopkins, and Kuppelwieser (2014) recommended to look at the $\mathrm{R}^{2}$, beta, and the corresponding t-values. We have shown the result of the model in Table 5 with the decision of acceptance/ rejection of the hypothesis. We have also considered the effect sizes of each relationship, which is the absolute values of the individual contributions of the corresponding predictor latent variables to the R-square coefficients of the criterion latent variable. This helps to ascertain whether the effects indicated by path coefficients are small, medium, or large, with recommended values of $0.02,0.15$, and 0.35 , respectively (Cohen, 1988).

Table 3 Measurement model statistics

\begin{tabular}{llllllllllllll}
\hline & FM & SM & ICON & IPub & HAnx & FAnx & EcAnx & REL & HAct & FAct & SecExpec & PriExpec \\
\hline Type & Ref & Ref & Form & Form & Form & Form & Form & Form & Form & Form & Form & Form \\
R-Squared & & 0.34 & 0.57 & 0.27 & 0.36 & 0.26 & & 0.15 & 0.63 & 0.53 & 0.64 & 0.29 \\
Reliability & 0.8 & 0.9 & 0.7 & 0.6 & 0.7 & 0.9 & 0.8 & 0.9 & 0.9 & 0.7 & 0.7 & 0.7 \\
AVE & 0.6 & 0.4 & 0.5 & 0.3 & 0.7 & 0.4 & 0.7 & 0.5 & 0.5 & 0.4 & 0.5 & 0.6 \\
\hline
\end{tabular}


Table 4 HTMT Ratio

\begin{tabular}{|c|c|c|c|c|c|c|c|c|c|c|c|}
\hline & FM & SM & $\mathrm{ICON}$ & IPub & HAnx & FAnx & EcAnx & REL & HAct & FAct & SecExpec \\
\hline \multicolumn{12}{|l|}{ FM } \\
\hline SM & 0.5 & & & & & & & & & & \\
\hline ICON & 0.6 & 0.6 & & & & & & & & & \\
\hline IPub & 0.5 & 0.2 & 0.3 & & & & & & & & \\
\hline HAnx & 0.4 & 0.3 & 0.5 & 0.3 & & & & & & & \\
\hline FAnx & 0.5 & 0.3 & 0.6 & 0.3 & 0.3 & & & & & & \\
\hline EcAnx & 0.2 & 0.2 & 0.2 & 0.3 & 0.7 & 0.2 & & & & & \\
\hline REL & 0.2 & 0.1 & 0.3 & 0.3 & 0.2 & 0.2 & 0.1 & & & & \\
\hline HAct & 0.2 & 0.3 & 0.3 & 0.3 & 0.7 & 0.2 & 0.4 & 0.1 & & & \\
\hline FAct & 0.6 & 0.5 & 0.6 & 0.7 & 0.4 & 0.4 & 0.2 & 0.3 & 0.6 & & \\
\hline SecExpec & 0.7 & 0.4 & 0.6 & 0.3 & 0.5 & 0.7 & 0.3 & 0.2 & 0.2 & 0.4 & \\
\hline PriExpec & 0.3 & 0.3 & 0.3 & 0.2 & 0.5 & 0.1 & 0.5 & 0.1 & 0.4 & 0.2 & 0.4 \\
\hline
\end{tabular}

\section{Results}

While exploring the decision of Food Hoarding and Health Action, the current study model explains $53 \%$ of the variance in the Food Hoarding Actions, where the positive effect of Food Anxiety $(\mathrm{B}=0.12)$, Information consumption $(\mathrm{B}=$ $0.259)$, FOMO $(\mathrm{B}=0.345)$ and the negative effect Gender $(\mathrm{B}=-0.183)$ were significant at $\mathrm{p}<.01$, while the positive effect of Social Media $(\mathrm{B}=0.078, p=0.062)$ was not significant. Hence, we are accepting H1b, H1f, H4d, and H8b but rejecting $\mathrm{H} 5 \mathrm{c}$. We were able to explain the $63 \%$ variance in Health Actions, where the positive effect of Health Anxiety ( $\mathrm{B}=0.674)$, Information Consumption $(\mathrm{B}=0.218)$, and Social Media $(\mathrm{B}=0.167)$ were significant at $p<.01$. The effect of FOMO $(\mathrm{B}=0.055, P=0.137)$ was not significant. Hence, we are accepting H1a, H1e, and H5b but rejecting $\mathrm{H} 4 \mathrm{c}$.

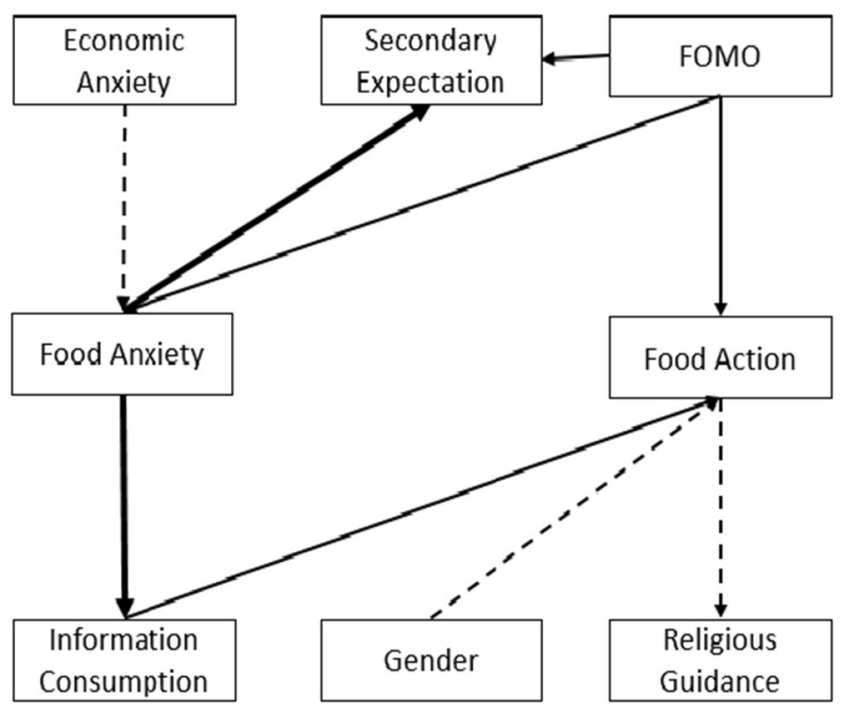

Fig. 2 Food Anxiety response model
Exploring the reasons for Health and Food anxiety, we were able to explain $26 \%$ of the variance in Food anxiety, where the positive effect of Economic Anxiety $(B=0.194)$ and FOMO $(\mathrm{B}=0.548)$ was significant at $p<.01$, while the effect of Gender $(\mathrm{B}=0.028, p=0.289)$ was not significant, which confirms that though female hoard food more but the food anxiety level is similar for both the gender. Hence, accepting $\mathrm{H} 2 \mathrm{~b}$ and $\mathrm{H} 4 \mathrm{~b}$ but rejecting $\mathrm{H} 8 \mathrm{a}$. For Health anxiety, we were able to explain $36 \%$ of the variance, where the positive effect of Economic Anxiety $(B=0.561)$ was significant at $\mathrm{p}<.01$, while the effect of FOMO $(\mathrm{B}=0.094)$ was significant at $\mathrm{p}<.05$, but the effect of Age $(\mathrm{B}=-0.069, P=0.088)$ was not significant. Hence, accepting $\mathrm{H} 2 \mathrm{a}$ and $\mathrm{H} 4 \mathrm{a}$ but rejecting $\mathrm{H} 7 \mathrm{~b}$.

Expectations from the Government being one of the decisive factors, our model was able to explain $29 \%$ of the variance of Primary expectations from the Government with the positive effect of Economic anxiety $(B=0.292)$, Health

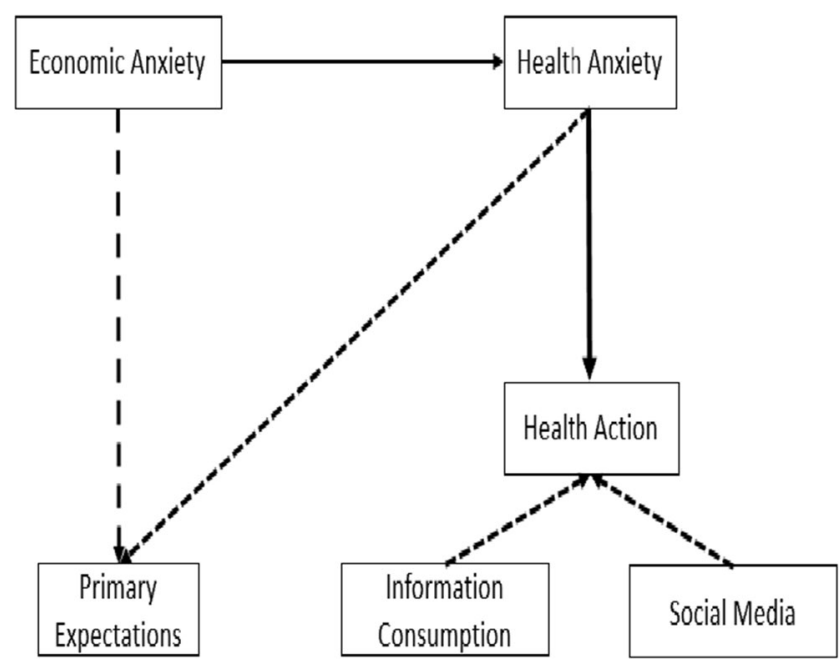

Fig. 3 Health Anxiety response model 
Table 5 Standard model results

\begin{tabular}{|c|c|c|c|c|c|c|c|c|}
\hline Нур & Relationship & Std Beta & $p$ value & Effect Size & Effect Scale & t-value & at $95 \%$ & at $99 \%$ \\
\hline H1a & HAnx-> HAct & 0.674 & $<0.001$ & 0.48 & $\mathrm{~L}$ & 14.49 & $\mathrm{~A}$ & $\mathrm{~A}$ \\
\hline $\mathrm{H} 1 \mathrm{~b}$ & FAnx- $>$ FAct & 0.12 & 0.009 & 0.063 & $\mathrm{~S}$ & 2.385 & A & $\mathrm{A}$ \\
\hline $\mathrm{H} 1 \mathrm{c}$ & HAnx-> ICon & 0.072 & 0.077 & 0.015 & N/A & 1.427 & $\mathrm{R}$ & $\mathrm{R}$ \\
\hline H1d & FAnx-> ICon & 0.355 & $<0.001$ & 0.228 & $\mathrm{~L}$ & 7.301 & $\mathrm{~A}$ & $\mathrm{~A}$ \\
\hline H1e & Icon- $>$ HAct & 0.218 & $<0.001$ & 0.087 & $\mathrm{~S}$ & 4.412 & A & A \\
\hline H1f & Icon- $>$ FAct & 0.259 & $<0.001$ & 0.162 & M & 5.265 & A & A \\
\hline $\mathrm{H} 2 \mathrm{a}$ & EAnx-> HAnx & 0.561 & $<0.001$ & 0.331 & M & 11.88 & A & A \\
\hline $\mathrm{H} 2 \mathrm{~b}$ & EAnx-> FAnx & 0.194 & $<0.001$ & 0.052 & $\mathrm{~S}$ & 3.896 & A & A \\
\hline $\mathrm{H} 2 \mathrm{c}$ & EAnx-> SecExpec & 0.041 & 0.21 & 0.01 & N/A & 0.808 & $\mathrm{R}$ & $\mathrm{R}$ \\
\hline $\mathrm{H} 2 \mathrm{~d}$ & EAnx-> PriExpec & 0.292 & $<0.001$ & 0.136 & $\mathrm{~S}$ & 5.962 & A & A \\
\hline $\mathrm{H} 3 \mathrm{a}$ & HAnx-> SecExpec & 0 & 0.498 & 0 & N/A & 0.004 & $\mathrm{R}$ & $\mathrm{R}$ \\
\hline $\mathrm{H} 3 \mathrm{~b}$ & HAnx-> PriExpec & 0.239 & $<0.001$ & 0.105 & $\mathrm{~S}$ & 4.847 & $\mathrm{~A}$ & A \\
\hline $\mathrm{H} 3 \mathrm{c}$ & FAnx-> SecExpec & 0.544 & $<0.001$ & 0.415 & $\mathrm{~L}$ & 11.5 & $\mathrm{~A}$ & $\mathrm{~A}$ \\
\hline $\mathrm{H} 3 \mathrm{~d}$ & FAnx-> PriExpec & 0.145 & 0.002 & 0.027 & $\mathrm{~S}$ & 2.894 & $\mathrm{~A}$ & $\mathrm{~A}$ \\
\hline $\mathrm{H} 4 \mathrm{a}$ & FM- > HAnx & 0.094 & 0.031 & 0.019 & $\mathrm{~N} / \mathrm{A}$ & 1.865 & A & $\mathrm{R}$ \\
\hline $\mathrm{H} 4 \mathrm{~b}$ & FM- > FAnx & 0.548 & $<0.001$ & 0.315 & M & 11.6 & A & A \\
\hline $\mathrm{H} 4 \mathrm{c}$ & FM- $>$ HAct & 0.055 & 0.137 & 0.012 & $\mathrm{~N} / \mathrm{A}$ & 1.096 & $\mathrm{R}$ & $\mathrm{R}$ \\
\hline $\mathrm{H} 4 \mathrm{~d}$ & FM- $>$ FAct & 0.345 & $<0.001$ & 0.22 & M & 7.084 & A & A \\
\hline $\mathrm{H} 4 \mathrm{e}$ & FM- $>$ SecExpec & 0.345 & $<0.001$ & 0.235 & $\mathrm{M}$ & 7.102 & A & A \\
\hline $\mathrm{H} 4 \mathrm{f}$ & FM-> PriExpec & -0.098 & 0.026 & 0.019 & N/A & -1.952 & A & $\mathrm{R}$ \\
\hline $\mathrm{H} 4 \mathrm{~g}$ & FM- $>$ ICon & 0.207 & $<0.001$ & 0.128 & $\mathrm{~S}$ & 4.185 & A & A \\
\hline $\mathrm{H} 4 \mathrm{~h}$ & FM- > IPub & 0.409 & $<0.001$ & 0.206 & $\mathrm{M}$ & 8.49 & $\mathrm{~A}$ & A \\
\hline $\mathrm{H} 4 \mathrm{i}$ & FM- $>$ SM & 0.511 & $<0.001$ & 0.291 & M & 10.75 & A & A \\
\hline $\mathrm{H} 5 \mathrm{a}$ & SM- > ICon & 0.315 & $<0.001$ & 0.196 & M & 6.45 & A & A \\
\hline $\mathrm{H} 5 \mathrm{~b}$ & SM- $>$ HAct & 0.167 & $<0.001$ & 0.049 & $\mathrm{~S}$ & 3.358 & A & A \\
\hline $\mathrm{H} 5 \mathrm{c}$ & SM- $>$ FAct & 0.078 & 0.062 & 0.041 & $\mathrm{~S}$ & 1.545 & $\mathrm{R}$ & $\mathrm{R}$ \\
\hline $\mathrm{H} 5 \mathrm{~d}$ & IPub- $>$ SM & 0.078 & 0.061 & 0.027 & $\mathrm{~S}$ & 1.553 & $\mathrm{R}$ & $\mathrm{R}$ \\
\hline $\mathrm{H} 5 \mathrm{e}$ & Icon- $>$ IPub & 0.152 & 0.001 & 0.061 & $\mathrm{~S}$ & 3.032 & A & $\mathrm{A}$ \\
\hline H6a & FAct- $>$ Rel & 0.221 & $<0.001$ & 0.078 & $\mathrm{~S}$ & 4.463 & A & A \\
\hline $\mathrm{H} 6 \mathrm{~b}$ & Icon- $>$ Rel & 0.14 & 0.003 & 0.045 & $\mathrm{~S}$ & 2.805 & A & $\mathrm{A}$ \\
\hline $\mathrm{H} 6 \mathrm{c}$ & FM- $>$ Rel & 0.072 & 0.077 & 0.022 & $\mathrm{~S}$ & 1.425 & $\mathrm{R}$ & $\mathrm{R}$ \\
\hline $\mathrm{H} 7 \mathrm{a}$ & Age- $>$ SM & -0.12 & 0.008 & 0.025 & $\mathrm{~S}$ & -2.398 & $\mathrm{~A}$ & $\mathrm{~A}$ \\
\hline $\mathrm{H} 7 \mathrm{~b}$ & Age- > HAnx & -0.069 & 0.088 & 0.011 & $\mathrm{~N} / \mathrm{A}$ & -1.358 & $\mathrm{R}$ & $\mathrm{R}$ \\
\hline $\mathrm{H} 8 \mathrm{a}$ & Gen- $>$ FAnx & 0.028 & 0.289 & 0.001 & N/A & 0.558 & $\mathrm{R}$ & $\mathrm{R}$ \\
\hline $\mathrm{H} 8 \mathrm{~b}$ & Gen- $>$ FAct & -0.183 & $<0.001$ & 0.046 & $\mathrm{~S}$ & -3.675 & A & A \\
\hline
\end{tabular}

Table 6 Model indices

\begin{tabular}{|c|c|c|}
\hline Model fit and quality indices & Value & Criteria \\
\hline Average R-squared (ARS) & 0.403 & $P<0.001$ \\
\hline Average block VIF (AVIF) & 1.449 & acceptable if $<=5$, ideally $<=3.3$ \\
\hline Average full collinearity VIF (AFVIF) & 2.223 & acceptable if $<=5$, ideally $<=3.3$ \\
\hline Tenenhaus GoF (GoF) & 0.479 & $\begin{aligned} \text { small }> & =0.1, \text { medium }>=0.25, \\
\text { large } & >=0.36\end{aligned}$ \\
\hline Sympson's paradox ratio (SPR) & 0.886 & acceptable if $>=0.7$, ideally $=1$ \\
\hline R-squared contribution ratio (RSCR) & 0.99 & acceptable if $>=0.9$, ideally $=1$ \\
\hline Statistical suppression ratio (SSR) & 1 & acceptable if $>=0.7$ \\
\hline Nonlinear bivariate causality direction ratio (NLBCDR) & 0.971 & acceptable if $>=0.7$ \\
\hline
\end{tabular}


Fig. 4 Anxiety response model during pandemic

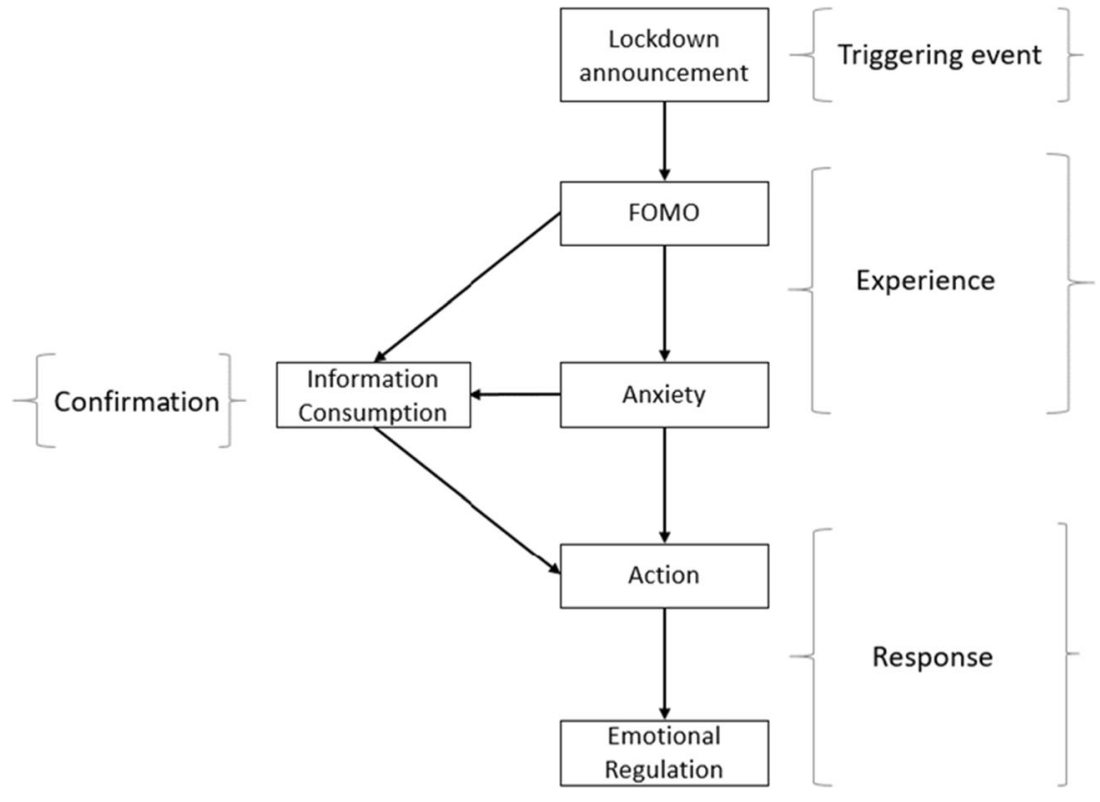

Anxiety $(\mathrm{B}=0.239)$, and Food Anxiety $(\mathrm{B}=0.145)$ were significant at $p<.01$ and the negative effect of FOMO $(\mathrm{B}=-$ 0.098 ) was significant at $p<.05$. Hence, accepting both $\mathrm{H} 2 \mathrm{~d}, \mathrm{H} 3 \mathrm{~b}, \mathrm{H} 3 \mathrm{~d}$, and H4f. We were able to explain the $64 \%$ of the variance of Secondary Expectations from the Government, where the positive effect of FOMO $(\mathrm{B}=0.345)$ and Food anxiety $(\mathrm{B}=0.544)$ were significant at $\mathrm{p}<.01$, while the effect of Health $(\mathrm{B}=0.041, p=0.21)$ and Economic $(\mathrm{B}=0, p=0.498)$ anxiety were not significant. Hence accepting both $\mathrm{H} 3 \mathrm{c}$ and $\mathrm{H} 4 \mathrm{e}$ but rejecting $\mathrm{H} 2 \mathrm{c}$ and H3a.

Considering the information construct, our model explained $57 \%$ variance in Information consumption, where the positive effect of Food Anxiety(B = 0.355), FOMO(B = $0.207)$, and Social Media $(B=0.315)$ were significant at $p<.01$ while the effect of Health Anxiety $(\mathrm{B}=0.072, P=$ 0.077 ) was not significant. Hence, accepting $\mathrm{H} 1 \mathrm{~d}, \mathrm{H} 4 \mathrm{~g}$, $\mathrm{H} 5 \mathrm{a}$, and rejecting H1c. Secondly, the model explained $27 \%$ of the variance of "Information publication," where the positive effect of $\mathrm{FOMO}(\mathrm{B}=0.409)$ and Information

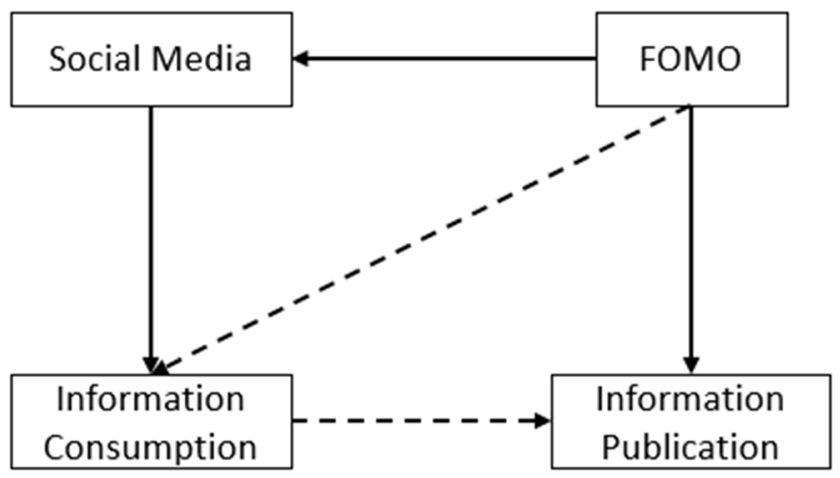

Fig. 5 Information construct during pandemic
Consumption $(\mathrm{B}=0.152)$ was significant at $p<.01$. Hence, accepting $\mathrm{H} 4 \mathrm{~h}$ and $\mathrm{H} 5 \mathrm{e}$. On Social media, we were able to explain 34\% variance in Social Media where the positive effect of FOMO $(B=0.511)$ and the negative effect of Age $(\mathrm{B}=-0.122)$ was significant at $p<.01$, but the effect of Information publication was not significant $(\mathrm{B}=0.078, p=$ 0.061 , hence accepting both $\mathrm{H} 4 \mathrm{i}$ and $\mathrm{H} 7 \mathrm{a}$ but rejecting $\mathrm{H} 5 \mathrm{~d}$. We found a significant increase in religious guidance as we were getting closer to lockdown. Our model was able to explain $15 \%$ variance in "Religious Guidance," where the positive effect of Food Hoarding Action (0.221) and Information Consumption (0.140) was significant at $p<.01$, while the effect of FOMO $(\mathrm{B}=0.072, P=0.077)$ was not significant. Hence accepting $\mathrm{H} 6 \mathrm{a}, \mathrm{H} 6 \mathrm{~b}$, and rejecting H6c. Below(Table 4), we have the Model indices, which shows the model fit parameters.

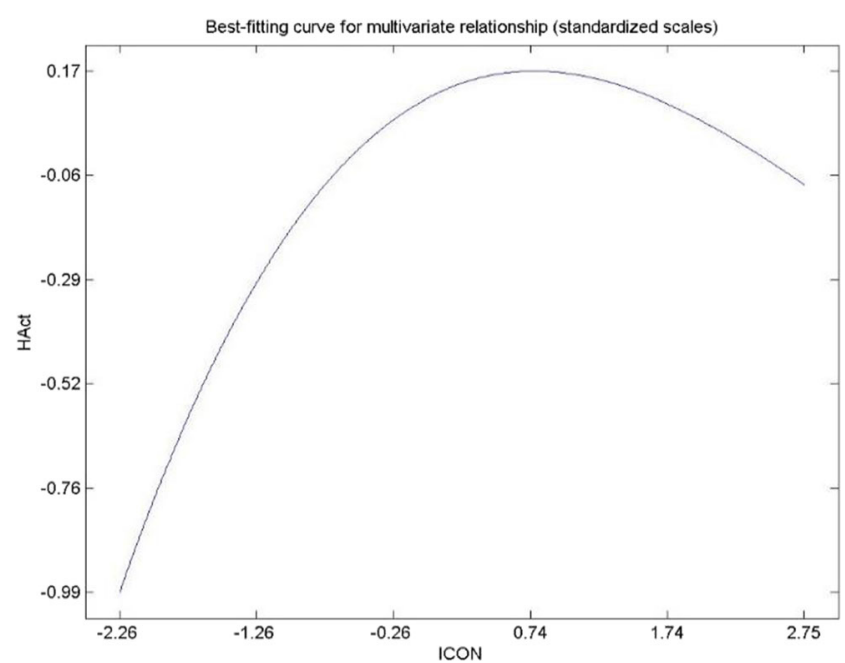

Fig. 6 ICon and HAct relationship 


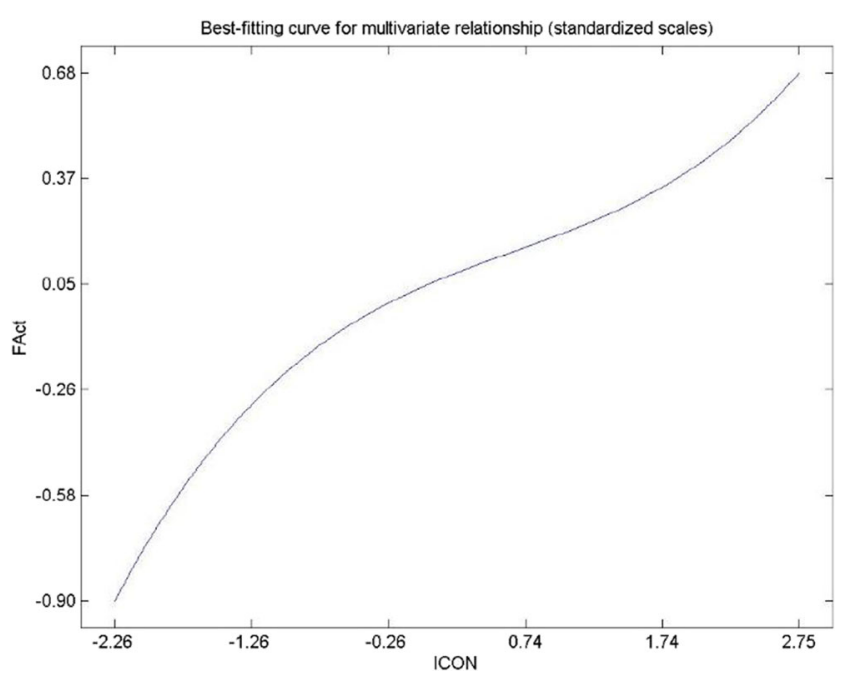

Fig. 7 ICon and FAct relationship

\section{Conclusion and Discussion}

Understanding the response to anxiety is a crucial step to optimize policy implementation in a crisis. We found that anxiety initiates actions, but the cause and effect mechanisms were different in Health and Food anxieties. Individuals facing food anxiety (Fig. 2) consume more information to confirm, and post-confirmation, they act to hoard food. Unlike the case of health anxiety(Fig. 3), the lockdown information itself was sufficient to confirm the criticality and trigger respective actions. Further, we found that Economic anxiety increases health anxiety, and individuals expect from Government to calm down the pandemic situation. This reflects the priority as well as the primary cause of health anxiety. Ensuring economic stability and controlling the spread of misinformation can help to calm down anxieties and their respective response mechanisms. In the relationships shown below, we have considered causal effect(b) above 0.15 and the arrow's boldness shows the strength of the effect size, Bold = Large, Simple = Moderate, Dash $=$ Small .

We found that individuals experience fear of missing access to food, which is reflected in their actions as they hoard food to ensure food availability. Individuals who experience this fear visit social media to confirm the uncertainty of food availability and others' actions, which, when confirmed, follow the herd and hoard the food. Here, anxiety doesn't result in actions directly but mediated through information consumption. We also found that females are more likely to hoard food than males; this reflects the effect of societal settings where females are responsible for running the kitchens at home. Interestingly, though females act more, the anxiety levels are the same for males and females. Unlike health, not the anxiety but FOMO and its effect on Information consumption are the drivers of food hoarding behavior. In the case of health, the effect of information and social media was negligible, and economic anxiety is the triggering factor for health anxiety, reflecting the economic consequences of falling sick with COVID19. Further, health anxiety and economic anxiety both have a significant effect on the precautionary behavior of individuals. This shows that few responses are driven by their respective anxiety, but some responses are not driven by a particular anxiety experience directly (Tables 5 and 6).

The systemic scale of problems in pandemic creates limitation in the capacity of individual to mitigate the problem, and individual often seek Government support. Here, we found segregation of factors and variables between health and food anxiety's response mechanism. We found that individuals who experience economic and health anxiety have a primary level of expectation from the Government. This primary level expectation is more realistic and focused on catering to the spread of the pandemic. Individuals who experience food anxiety and especially FOMO have the overreactive secondary level expectations from the Government. This suggests that individuals who experience a realistic level of reactiveness to the pandemic situation will experience economic and health anxiety and will act accordingly, but those with a higher level of reactiveness due to more information consumption in this situation will hoard food and further have unrealistic expectations from the Government.

In the context of the information construct, we found the possibility of a cyclical flow of information. We found that FOMO is the driving force of this construct as it has a significant positive effect on all three checkpoints of information consumption, social media, and information publication. We found the lockdown announcement was sufficient for triggering of FOMO and the experience of FOMO pushed individuals to consume more information on social media to confirm the level of uncertainty. We further found that individuals who consume information also publishes information on social media, suggesting the possibility of the cyclical flow of information during pandemics.

During a pandemic, a situation may arise when even government support cannot work, and individuals may seek support from higher powers. We found that those who consume more information have a higher desire to look for religious guidance during the COVID19 pandemic. This reflects that a higher level of fear may push individuals to seek support from a higher power, suggesting three levels of expectations in a response mechanism. In addition to this, we further found that individuals who hoard food seek religious guidance. This suggests the self-assessment of actions that the impact of food hoarding can have on society. Individuals experience ethical ambiguity during self-focused action of food hoarding and seek religious guidance.

Unlike the prevailing trend during the time when sample was collected, older people do not observe a higher level of health anxiety. This reflects that with age, the experience has 
taught them a realistic approach towards pandemics. Though, they were vulnerable to the disease, the net effect is less anxiety. Further, social media usage is lower among elders, hence they are less vulnerable to misinformation.

We also found that, though Information consumption increases health action, after a peak, it stabilizes, as the positive effect of information consumption reduces(Fig. 6). However, the case with food action is different(Fig. 7), and the effect of information continues without flattening. We infer that the effect of information consumption dilutes with increased health actions, but in food actions, it continues to increase without any limit.

Above suggested model (Fig. 4) is the response mechanism during pandemic. Response to anxiety at the individual level can cause a systemic problem at a country level. Policymakers should understand the change in the response mechanism of different types of anxieties and the role of information construct in a specific type of anxiety. Authorities should control the spread of misinformation to check the hoarding of food essentials. To improve the nation's mental health, governments should provide economic support to the citizens as economic anxiety is the fundamental reason for driving health anxiety. Results will be helpful to plan and control pandemic related anxieties as well as the expected problems of resources that response mechanism can bring collectively (Figs. 5, 6 and 7).

\section{Limitations}

Due to multiple factors considered, we have used a selfdesigned scale and often with less number of indicators which has compromised AVE. Though our results are significant statistically, an improved scale can give more accurate results. Further, due to the prevailing stress, we could not manage much participation, which reduced the number of samples. We expect the results to improve with an increase in the number of participants.

\section{Compliance with Ethical Standards}

Ethical Approval All procedures performed in studies involving human participants were in accordance with the ethical standards of the institutional and/or national research committee and with the 1964 Helsinki declaration and its later amendments or comparable ethical standards.

Informed Consent Informed consent was obtained from all individual participants included in the study.

Conflict of Interest The author declares that he/she has no conflict of interest.

\section{References}

Asmundson, G. J., \& Taylor, S. (2020). How health anxiety influences responses to viral outbreaks like COVID-19: What all decisionmakers, health authorities, and health care professionals need to know. Journal of Anxiety Disorders, 71, 102211.

Barchard, K. A., \& Williams, J. (2008). Practical advice for conducting ethical online experiments and questionnaires for United States psychologists. Behavior Research Methods, 40(4), 1111-1128.

Beck, A. T., \& Clark, D. A. (1997). An information processing model of anxiety: Automatic and strategic processes. Behaviour Research and Therapy, 35(1), 49-58.

Clark, L, A., \& Watson, D. (1995). Constructing validity: Basic issues in objective scale development. Psychological Assessment, 7, 309 319.

Cohen, J. (1988). Statistical power analysis for the Behavioural sciences. New York, NY: Routledge Academic.

Davidson, H. (2020). First Covid-19 case happened in November. The Guardian: China government records show - report.

Dong, L., \& Bouey, J. (2020). Public mental health crisis during COVID19 pandemic, China. Emerging Infectious Diseases, 26(7), 10 3201.

Duan, L., \& Zhu, G. (2020). Psychological interventions for people affected by the COVID-19 epidemic. The Lancet Psychiatry, 7(4), 300-302.

Fornell, C., \& Larcker, D. F. (1981). Evaluating structural equation models with unobservable variables and measurement error. Journal of Marketing Research, 18(1), 39-50.

Gholami, R., Sulaiman, A. B., Ramayah, T., \& Molla, A. (2013). Senior managers' perception on green information systems (IS) adoption and environmental performance: Results from a field survey. Information \& Management, 50(7), 431-438.

Gurland, J., \& Tripathi, R. C. (1971). A simple approximation for unbiased estimation of the standard deviation. The American Statistician, 25(4), 30-32.

Gustafsson, A., \& Johnson, M. D. (2004). Determining attribute importance in a service satisfaction model. Journal of Service Research, $7(2), 124-141$.

Hair Jr, J, F., Sarstedt, M., Hopkins, L., \& Kuppelwieser, V, G. (2014). Partial least squares structural equation modeling (PLS-SEM): an emerging tool in business research. European Business Review, 26(2), 106-121.

Henseler, J., Ringle, C. M., \& Sarstedt, M. (2015). A new criterion for assessing discriminant validity in variance-based structural equation modeling. Journal of the Academy of Marketing Science, 43, 115135.

Hofmann, S. G., Ellard, K. K., \& Siegle, G. J. (2012). Neurobiological correlates of cognitions in fear and anxiety: A cognitiveneurobiological information-processing model. Cognition \& Emotion, 26(2), 282-299.

Huang, Y., \& Zhao, N. (2020). Generalized anxiety disorder, depressive symptoms and sleep quality during COVID-19 outbreak in China: a web-based cross-sectional survey. Psychiatry Research, 112954.

Joseph, S., \& DiDuca, D. (2007). The dimensions of religiosity scale: 20item self-report measure of religious preoccupation, guidance, conviction, and emotional involvement. Mental Health, Religion and Culture, 10(6), 603-608.

Kline, R. B. (2011). Principles and practice of structural equation modeling. New York: Guilford Press.

Kock, N. (2017). WarpPLS user manual: Version 6.0. Laredo, TX: ScriptWarp Systems.

Kock, N. (2020). WarpPLS user manual: Version 7.0. Laredo, TX: ScriptWarp Systems. 
Lam, L. W. (2012). Impact of competitiveness on salespeople's commitment and performance. Journal of Business Research, 65(9), 13281334.

McCauley, M., Minsky, S., \& Viswanath, K. (2013). The H1N1 pandemic: Media frames, stigmatization and coping. BMC Public Health, 13(1), 1116.

Paules, C. I., Marston, H. D., \& Fauci, A. S. (2020). Coronavirus infections-More than just the common cold. Jama, 323(8), 707708.

Przybylski, A. K., Murayama, K., DeHaan, C. R., \& Gladwell, V. (2013). Motivational, emotional, and behavioral correlates of fear of missing out. Computers in Human Behavior, 29(4), 1841-1848.

Rajkumar, R. P. (2020). COVID-19 and mental health: A review of the existing literature [published online ahead of print, 2020 Apr 10]. Asian Journal of Psychiatry, 52, 102066.

Ringle, C, M., Wende, S., \& Will, A. (2005). SmartPLS 2.0 M3 Beta.

Sahin, C. (2018). Social media addiction scale-student form: The reliability and validity study. Turkish Online Journal of Educational Technology-TOJET, 17(1), 169-182.

Shigemura J., Ursano R, J., Morganstein J, C., Kurosawa M., Benedek D, M. (2020) Public responses to the novel 2019 coronavirus (2019-
$\mathrm{nCoV})$ : mental health consequences and target populations. Psychiatry and Clinical Neurosciences, 74(4), 281.

Wilson, M, E., \& Chen, L, H. (2020). Travellers give wings to novel coronavirus (2019-nCoV). Journal of Travel Medicine, 27(2).

Wold, H. O. A. (1982). Soft modeling: The basic design and some extensions. In K. G. Jöreskog \& H. O. A. Wold (Eds.), Systems under indirect observations: Part II (pp. 1-54). Amsterdam: NorthHolland.

Zandifar, A., \& Badrfam, R. (2020). Iranian mental health during the COVID-19 epidemic. Asian Journal of Psychiatry, 51, 101990.

Zerafati Shoae, N., Omidvar, N., Ghazi-Tabatabaie, M., Houshiar Rad, A., Fallah, H., \& Mehrabi, Y. (2007). Is the adapted Radimer/ Cornell questionnaire valid to measure food insecurity of urban households in Tehran, Iran? Public Health Nutrition, 10(8), 855861.

Publisher's Note Springer Nature remains neutral with regard to jurisdictional claims in published maps and institutional affiliations. 